\title{
Comparison of Environmental Science Learning Outcomes Using Research-Based Learning for Biology Students
}

\author{
Sueb \\ Department of Biology, Faculty of Mathematics and Natural Sciences \\ Universitas Negeri Malang \\ Malang, Indonesia \\ sueb.fmipa@um.ac.id
}

\begin{abstract}
The use of research-based learning in environmental science course has been done since a long time ago. Research-based learning enforced students to conduct group research based on their topic. The purpose of the research is to identify the outcomes of environmental science learning via research-based learning method for biology students. The research is a comparative study using four classes in 2016 academic year covering 126 students. Kruskal Wallis method was used for the data analysis because the data were not normally distributed. The result is $p=0.000<\alpha(0.05)$, which means there is a difference in students' learning outcomes after using the research-based learning method. The conclusion of the research is there is a difference of environmental science learning outcomes after using research-based learning approach for biology students.
\end{abstract}

Keywords-Environmental science, Learning outcomes, research based learning, Biology students

\section{INTRODUCTION}

Students have many activities. However, some students cannot do anything. Even many students have not read anything, and some of them do not have frequent reading time. To overcome such problems, one way that can be implemented is to force them to read some references that support their study in university. Therefore, the researchers have done some activities that make students diligent to read and study hard in university. Apparently, we make some activities that make students conduct a project or research. The project is usually done in groups. The project is done via research-based learning. Dekker and Wolff (2016) suggested that universities can improve the relevance of their education and can better prepare the students for follow-up studies and to the new and emerging demands of the labor market in the twenty-first century.

Research-based learning has many definitions. Tremp expressed steps of RBL as formulating a general question, overviewing research-literature, defining the question, planning research activities, clarifying research methods/methodologies, undertaking an investigation, analyzing data, making interpretation and consideration of results, and report and presentation of results [1]. Dekker and Wolff used the term of research-based teaching [2].

Dekker and Wolff concluded learning from research is when students acquire knowledge of critical theories and research in their fields of discipline [2]. Learning about research means that students gain knowledge of methods and techniques of research in courses and research labs. Learning through research means that students acquire knowledge of their disciplines by doing the research themselves.

Some researcher used the term of research-based instruction. Choeisuwan stated that research-based instruction is the teaching and learning process that incorporates research elements into the program [3]. The core principle of the instruction focuses on students' acquisition. In other words, the research-based instruction equips students with the skills and abilities to acquire knowledge by themselves rather than spoonfeeds them the subject-matter.

In this research, we used the term of research-based learning that leads to two steps. In the first step, students gave presentations of theories used in their paper. Afterwards, students in groups developed their research papers. It is usually called proposals. However, we do not use this term in order not to make the students feel like conducting research. They should consult the development of their research papers with their lecturer. If their plan of research is assumed as appropriate according to their lecturer, they could directly conduct research based on their plan.

The research-based learning in this research was applied in an environmental science course. Environmental science is a multidisciplinary science of combining human mind and behavior with the environment. It is in line with Miller and Spoolman statement that environmental science is an interdisciplinary study of how humans interact with living and nonliving parts of their environment [4]. Meanwhile, Miller and Spoolman stated that environmental science is an interdisciplinary study of how the earth works, how we interact with the earth, and how we can deal with the environmental problems that we face [5]. Environmental issues affect every part of our lives and even our body. 


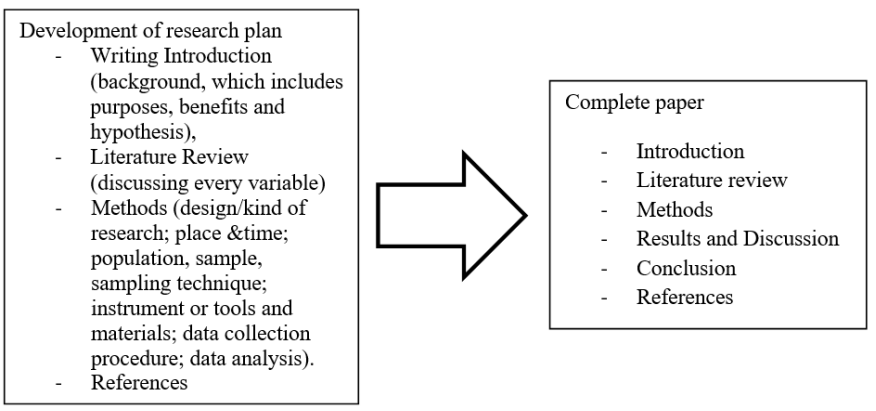

Fig. 1. Development of Research Plan

According to the above background, we conducted this research. It was conducted to compare Environmental Science Learning Outcomes Using Research-Based Learning for Biology Students. It was applied for biology students because this course is programmed for them.

\section{METHOD}

This research used one-shot experimental case study with some modifications using four groups (classes) [6]. The samples are from 4 classes of biology (3 classes of biology education students and 1 class of biology students) of 2016 academic year who attended the course of environmental science (ES) in 2016/2017 odd semester. The technique used in taking samples was cluster sampling. In this research, we used research-based learning (RBL). In using this method, students were divided into some groups. The RBL method applied to four classes was as follow. The data analyses used are a mean and standard deviation and analysis of variance (ANOVA). Because the data were not normally distributed, we used the alternative of Kruskal Wallis test.

\section{RESULT}

Based on Table 1, it can be seen that the mean scores of Environmental Science from 4 class (A, B, C, I) of $\mathrm{N}=126$ students from Department of Biology was 3.09.

TABLE I. DESCRIPTIVE STATISTICS OF ES SCORE OF DEPARTMENT OF BIOLOGY

\begin{tabular}{|l|r|r|r|r|r|}
\hline & \multicolumn{1}{|c|}{$\mathbf{N}$} & \multicolumn{1}{|c|}{ Mean } & $\begin{array}{c}\text { Std. } \\
\text { Deviation }\end{array}$ & Minimum & Maximum \\
\hline SCORE & 126 & 3.0929 & .61931 & .00 & 4.00 \\
\hline
\end{tabular}

TABLE II. MEAN RANK OF ES LEARNING OUTCOMES

\begin{tabular}{|c|c|c|}
\hline CLASS & $\mathbf{N}$ & Mean Rank \\
\hline $\begin{array}{ll}\text { SCORE } & 1\end{array}$ & 32 & 91.06 \\
\hline 2 & 35 & 60.07 \\
\hline 3 & 30 & 63.32 \\
\hline 4 & 29 & 37.41 \\
\hline Total & 126 & \\
\hline
\end{tabular}

TABLE III. KRUSKAL WALLIS TEST RESULTS OF ES LEARNING OUTCOMES BASED ON RESEARCH-BASED LEARNING

\begin{tabular}{|l|r|}
\multicolumn{2}{|c|}{ Test Statistics $^{\mathrm{a}, \mathrm{b}}$} \\
\hline Chi-Square & \multicolumn{1}{c|}{ SCORE } \\
\hline Df & 34.705 \\
\hline Asymp. Sig. & 3 \\
\hline
\end{tabular}

a. Kruskal Wallis Test

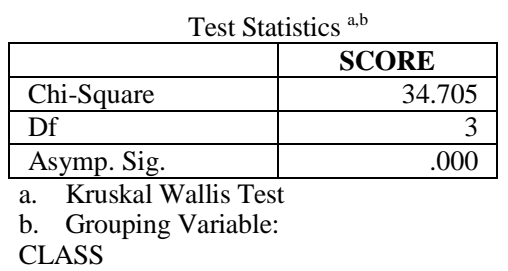

Based on Table 2, it can be viewed that the mean rank of Class A (1) is the highest, followed by Class C (3), class B (2), and the last one is class D. Class A had done the assignment more excellently than the others. Some groups from this class were diligent in consulting with their teacher.

Based on Table 3, it appears that the Kruskal Wallis test resulted in $p=0.000<\alpha(0.05)$. It means that there was a difference in the ES learning outcomes in the form of scores of the students from different classes. The use of research-based learning causes different scores. Students from a group that conducted proper research would have good or even excellent scores. Another meaning of RBL has affected ES learning outcomes. Such results are supported by Fernate et al. stated that research-based academic studies allow students to develop their research-related capabilities by promoting critical scientific thinking, problem-solving and using other analytic strategies and technical tools [7]. It enables students to place their learning within a meaningful context, establish an environment that encourages and supports research and emphasizes the synergy between research activity and learning in interdisciplinary research fields. It is also similar to Sota and Peltzer statement that RBL among master degree students through the assignment for research by searching from journal and reading, analyzing, synthesizing as well as giving presentations and holding a discussion together made students increase their cognitive, knowledge, ethics, social skills, communication, arithmetic, and information technology skills, satisfaction and information seeking skill [8].

Universities could improve the relevance of their education and can better prepare the students for follow-up studies and to new and emerging demands of the labor market in the twentyfirst century [2]. Moreover, a close connection between teaching and research strengthens their identity. The results of research conducted by Toom et al. indicated that educators appreciate the research-based approach as the main organizing theme [9]. Most of the respondents thought that a five-year study program with a Master degree was an appropriate qualification for a primary school teacher. They also felt that this approach was best to be realized in the students' research work.

The results of a study done by Srikoona et al. showed that the data clearly demonstrated the mean of the effect of 
research-based learning which can enhance the scores of the experimental group on independent variables (knowledge and skills, good citizen, thinking skills, achievement, natural science researcher, basic research, problem-solving skills, critical thinking and inquiry, exempt attitudes) [10]. It is similar to our research. It is also supported by Wannapiroon stating that the research-based learning model appears to provide strong support for the premise that a research-based learning and teaching approach could provide strong support for developing graduate students' research competency and critical thinking skills [11].

\section{CONCLUSION}

There was a difference of learning outcomes in environmental science course using the research-based learning method. It is suggested that research-based learning method should be better for use in the learning activity.

\section{REFERENCES}

[1] P. Tremp, "Research-based Teaching and Learning A LERU project, University of Zurich," Cent. Univ. Teach. Learn., 2010.

[2] H. Dekker and S. W. Wolff, "Re-inventing Research-Based Teaching and Learning," in presentation at the meeting of the European Forum for Enhanced Collaboration in Teaching of the European University Association, 2016.
[3] V. Choeisuwan, "Effects of Research-based Instruction in Health System Subject of Nursing Students, the Royal Thai Navy College of Nursing," Procedia-Social Behav. Sci., vol. 191, pp. 948-952, 2015.

[4] G. T. Miller and S. E. Spoolman, Environmental Science. Belmont, CA: Brooks/Cole, 2010.

[5] G. Miller and S. Spoolman, Living in the Environment, Sixteenth. Belmont, CA: Brooks/Cole, 2009.

[6] P. D. Leedy and J. E. Ormrod, Practical Research Planning and Design, 8th Editio. Upper Saddle River, New Jersey: Pearson Merrill Prentice Hall, 2005.

[7] A. Fernate, S. Surikova, D. Kalnina, and C. Sanchez Romero, "Research-based academic studies: Promotion of the quality of learning outcomes in higher education," in The European Conference on Educational Research, 2009, pp. 1-23.

[8] C. Sota and K. Peltzer, "The Effectiveness of Research Based Learning among Master degree Student for Health Promotion and Preventable Disease, Faculty of Public Health, Khon Kaen University, Thailand," Procedia-Social Behav. Sci., vol. 237, pp. 1359-1365, 2017.

[9] A. Toom et al., "Exploring the essential characteristics of research-based teacher education from the viewpoint of teacher educators," in Proceedings of Second Annual Teacher Education Policy in Europe Network (TEPE) Conference: Mapping the landscape and looking to the future., 2008.

[10] S. Srikoon, T. Bunterm, J. Samranjai, and J. Wattanathorn, "Research Synthesis of Research-based Learning for Education in Thailand," Procedia-Social Behav. Sci., vol. 116, pp. 913--917, 2014.

[11] P. Wannapiroon, "Development of research-based blended learning model to enhance graduate students' research competency and critical thinking skills," Procedia-Social Behav. Sci., vol. 136, pp. 486-490, 2014.

[12] 